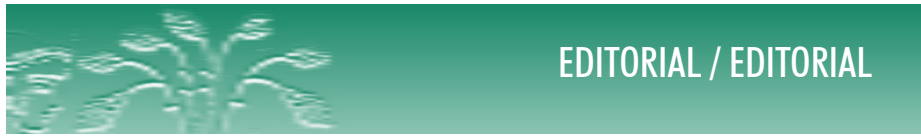

DOI: 10.12957/demetra.2018.32191

\title{
A globalização e a divulgação da pesquisa científica: concentração de editoras e implicações sobre diferentes campos da ciência
}

\section{Globalization and dissemination of scientific research: concentration of publishers and implications on different fields of Science}

No mundo globalizado, crescem as fusões de corporações no sentido de unificar os mercados em escala planetária. A divulgação do conhecimento científico não foge a esse padrão.

Artigo publicado em 2015 na conceituada revista científica PlosOne, ${ }^{1}$ abordando a consolidação da indústria editorial científica no período de 1973 a 2013, mostra o crescimento de seis editoras comerciais - Elsevier, Blackwell, Springer, Taylor \& Francis, American ChemicalSociety e Sage -, em especial a partir de incorporações de editoras menores. Em 2013, cinco desses editores cobriam mais da metade de todos os trabalhos divulgados através da Web of Science. Tal concentração editorial se expressa de modos diferentes nos distintos campos de produção do conhecimento científico.

Nas Humanidades e Artes, apenas 20\% dos artigos foram publicados através desse grupo de editoras comerciais ao final do período tomado para análise. Destacam os autores que isto se dá por ser comum, nesses campos científicos, publicar em livros ou em periódicos locais, não sendo, segundo o estudo, lucrativo para as grandes editoras explorar essas áreas cujos "produtos" não se espraiam para o mundo todo, como acontece com a Biomedicina, por exemplo. De alguma forma, esse campo das Humanidades e Artes resguarda certa independência em relação a esses oligopólios em seu franco processo de concentração editorial.

A Física e a Química ficam com os menores percentuais de publicações nessas empresas por outros motivos - a saber, a força das sociedades científicas nesses campos, que investem na cultura de publicações em acesso aberto na modalidade pre-print.

1 Larivière, Vincent; Haustein, Stefanie; Mongeon, Philippe.The Oligopoly of Academic Publishers in the Digital Era. Plos One. June 10, 2015. https://doi.org/10.1371/journal.pone.0127502 
A Biomedicina parece situar-se no roldão das tendências de interesse para essas corporações. Similarmente, nas Ciências Sociais Aplicadas, a concentração dos artigos nessas editoras passou de $15 \%$ em 1995 para $66 \%$ em 2013.

Discutindo esse mesmo artigo, o "Oxigênio"² considera que

O problema desse oligopólio de editoras comerciais é que a comunidade científica fica dependente do sistema. Nesse ambiente, os pesquisadores são pressionados a publicar em revistas de alto impacto, o que pode interferir até em seus objetos de pesquisa. Outro problema é o lucro abusivo dessas editoras. Elas diminuíram gastos com impressão e distribuição a partir da publicação digital, mas ainda cobram pela submissão de artigos, que são os produtos vendidos mundialmente por meio de assinaturas. Para se ter uma ideia, as bibliotecas acadêmicas são responsáveis por até $75 \%$ das receitas dessas editoras.

A dependência da comunidade científica evidencia-se, por exemplo, na preocupação atual relativa à manutenção do Portal de Periódicos Capes neste ano de 2018, por parte de entidades e sociedades científicas brasileiras, conforme carta enviada recentemente ao presidente da Capes, assinada pela Academia Brasileira de Ciências (ABC), Associação Nacional de Dirigentes de Instituições Federais de Ensino Superior (ANDIFES) e Sociedade Brasileira para o Progresso da Ciência (SBPC). ${ }^{3} \mathrm{O}$ impedimento ao livre acesso proporcionado pela Capes aos pesquisadores e estudantes pode se dar se rompidos os acordos remuneratórios com essas corporações editoriais -neste caso, os pesquisadores passam a ter que pagar pelo acesso aos artigos periódicos situados em sua linha de interesses. Isso pode se dar com os recursos destinados ao financiamento de seus projetos de pesquisa, ou seja, reduzindo os valores para experimentos ou trabalhos de campo, prejudicando o desenvolvimento dos trabalhos correspondentes. Outra opção reside no pagamento com recursos próprios do pesquisador, o que expressa os caminhos da desvalorização da ciência nacional.

DEMETRA tem buscado os caminhos da publicação em acesso aberto como sua base editorial. Sustenta-se o periódico por meio de financiamentos públicos, ainda que nos tempos mais recentes os esteja vendo minguar ano após ano. Como investimento interdisciplinar, tem implementado esforços no sentido de propiciar lugar para aqueles campos emergentes da ciência nacional que não encontram espaço junto aos interesses de cunho lucrativo, que, em geral, marcam as grandes corporações editoriais acima aludidas: é o caso das Humanidades, quando lidam com a alimentação e com o corpo simbolizado, ambos tomados como mediadores de relações sociais; também os debates

2 "Oxigênio" é o programa de jornalismo e divulgação científica produzido em parceria entre o Laboratório de Estudos Avançados em Jornalismo (LABJOR) e a Web Rádio Unicamp, ambos da Universidade Estadual de Campinas (UNICAMP). Disponível em: http://oxigenio.comciencia.br/o-oligopolio-das-editoras-deperiodicos-cientificos-e-a-pressao-por-publicacoes-dos-cientistas/. Acesso em: 03 mar 2018.

3 Disponível em: http://jcnoticias.jornaldaciencia.org.br/wp-content/uploads/2017/09/carta-\%C3\%A0-Capessobre-o-Portal-de-Peri\%C3\%B3dicos-12-09-2017-SBPC-ANDIFES-ABC.jpg. Acesso em: 03 mar 2018. 
acerca de Políticas Sociais, incluindo aquelas expressões de caráter mais local, porém inovador no cenário nacional; ou ainda os estudos situados no âmbito da Alimentação para Coletividades. Todos os campos de produção de conhecimento científico contam com lugar entre nós; contudo, estes em particular - Humanidades, Políticas Sociais e Alimentação para Coletividades - merecem especial atenção como estímulo ao seu desenvolvimento.

Seguindo por caminhos muito distintos desses que marcam as grandes fusões internacionais, DEMETRA situa-se na contramão dos interesses comerciais, estando nossos esforços editoriais dirigidos ao fortalecimento da ciência, seja ela já consolidada ou em seus encaminhamentos iniciais. Temos promovido, anualmente, chamadas para números temáticos voltados para o campo das Humanidades. E estamos abertos a iniciativas similares em outros espaços da ciência, guardando os princípios do acesso aberto na disseminação do conhecimento científico.

Shirley Donizete Prado e Fabiana Bom Kraemer Editoras 
